\title{
LEUCISTIC CACKLING
IN WASCANA LAKE
}

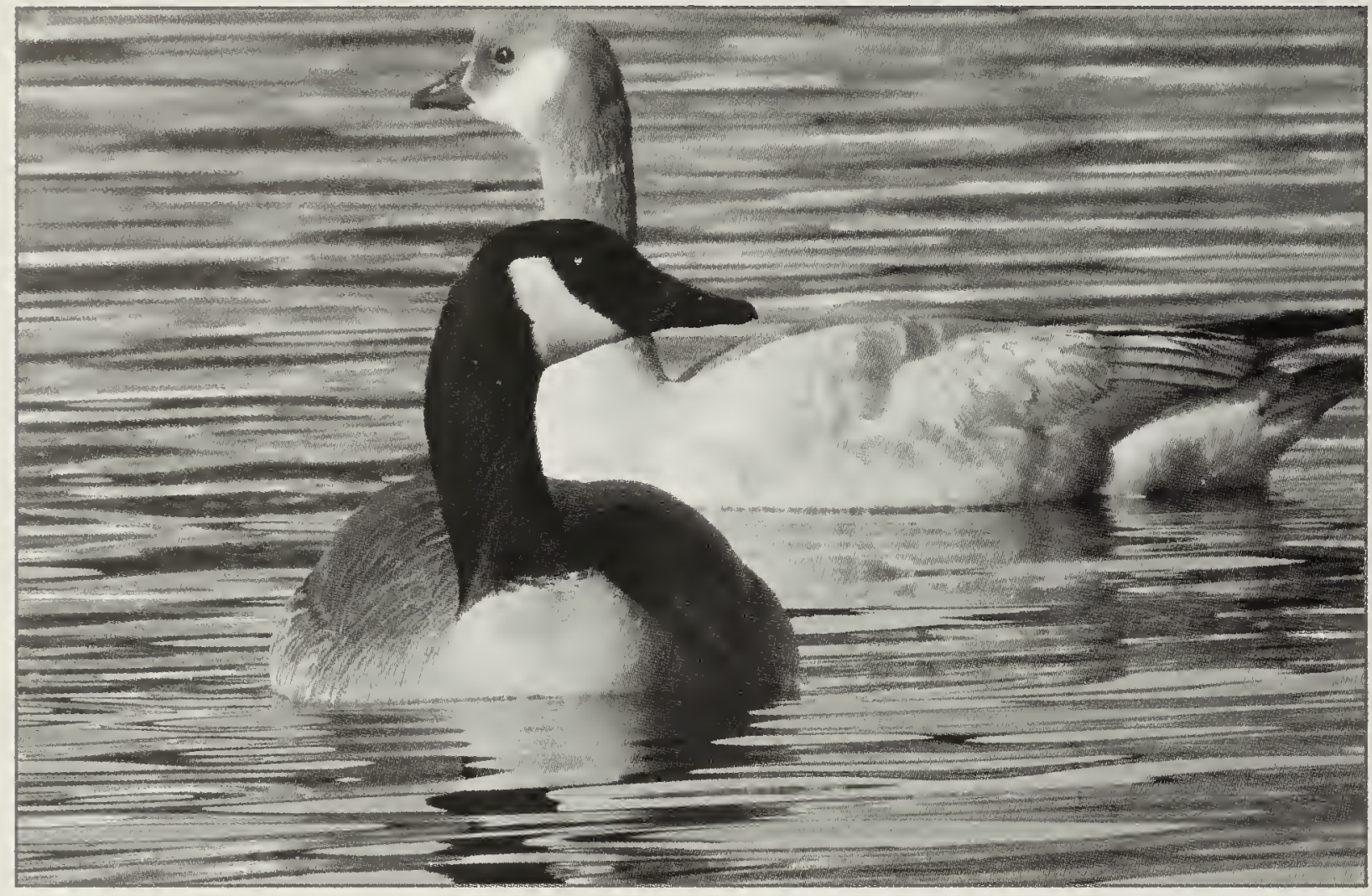

Brian Sterenberg

2336 Montreal Street

Regina, SK S4T 3K5

brian01@sasktel.net

A leucistic cackling goose (Branta

hutchinsii) was observed in

Wascana Lake between Pine and

Spruce Islands $\left(50^{\circ} 25^{\prime} 39.2^{\prime \prime} \mathrm{N}\right.$

$\left.104^{\circ} 36^{\prime} 286^{\prime \prime} \mathrm{W}\right)$ at 17:00 $\mathrm{h}$ on

March 23, 2016. One photo (below) shows the leucistic goose alone, while the other shows the leucistic goose with a normally pigmented Canada goose for contrast. $\ell$

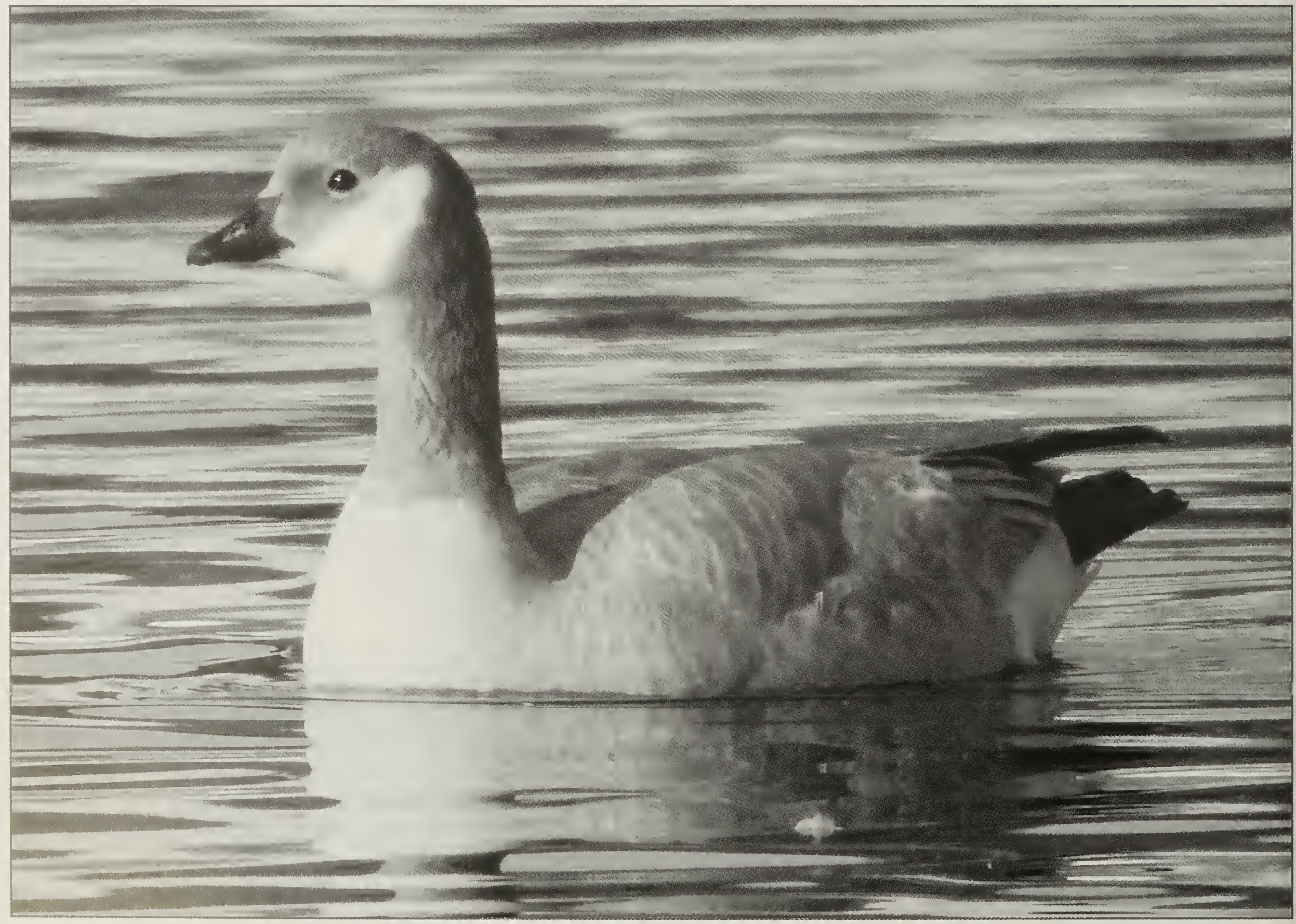

Photo credit: Brian Sterenberg 